\title{
Attitude of the Community towards Birth Spacing: A Case Study of District Swabi, Province Khyber Pakhtoonkhaw, Pakistan
}

\author{
Muhammad Ibrar and Raazia Hassan Naqvi
}

\begin{abstract}
Health is regarded as the top most priority of every individual, but no specific concern has been given to the health of a layman particularly in the reproductive side. Lack of knowledge and awareness among the local masses boost the problems of reproductive health particularly in the rural setups and no importance has been given to the birth spacing due to which the health and nutrition problems both in females and children are at its peak. The three aspects of our society i.e. culture, social and religious; all has played a negative role in this regard, people are unaware of the teaching of Islam regarding this issue and culture and social aspects also played a negative role in this respect. District Swabi where the education ratio is highest than as compared with other districts of the Province Khyber Pakhtoonkhaw, is also confronting this problem of birth spacing. The study showed that most of the people believed that the methods of family planning that can be used for birth spacing actually stop the reproduction ability of the couple for the future. Despite of all these issues the government has also not played a vital role to overcome the problems in reproductive health sector.
\end{abstract}

Index Terms-Health, lack of awareness, misconceptions, reproductive health.

\section{INTRODUCTION}

In the era of industrialization when people are suffering from so many diseases, the problems of reproductive health are at its peak and no proper concerns have been given to it. Still the mortality rate in our country is at maximum level because no attentions have been given to the issue of reproductive health. The problem of birth spacing is one of the main issues in this regard and definitely the most critical one for our society. Birth spacing can simply be defined as the time of waiting between two pregnancies, a woman may need rest for another pregnancy after having a delivery for at least two years [1].

According to UNDP's Human Development Report 2013 [2], Pakistan ranks 146 in human development index along with Bangladesh who is also at 146, whereas India is at 136, Canada at 11 and United States of America is at 3 and Norway is at the top. Other related indicators as in [2] are as follows: Table I

The importance of stable population cannot be underestimated in the country like Pakistan, hence from its independence the government has adopted various policies

Manuscript received October 10, 2013; revised January 11, 2014.

Muhammad Ibrar is with the Department of Social Work, Institute of Social Work, Sociology \& Gender Studies, University of Peshwar, Khyber Pakhtunkhaw, Pakistan (e-mail: ibrarsworker@yahoo.com). to have a stable population but unfortunately with various socio-economic and cultural problems the government is unable to achieve the desired goals [3].

Islam gives prime importance to the family and considers it as the basic social unit and also highlighted the duties of husband and wife. The advantages of birth spacing are that a mother may feed her child for the time which has been mentioned by Islam and also having a safe time for another pregnancy [4]. But unfortunately no proper concern has been given to the issue of birth spacing.

Those pregnancies which are not planned make women vulnerable to many diseases and sometimes cause their death in Pakistan. Birth spacing provides a woman an appropriate time to recover her nutritional needs which have been affected by regular pregnancies [5]. Shorter time in pregnancies can cause 'maternal depletion syndrome' which results in anemia. Maternal mortality rate in our country is 276 per 100,000 births but it may be more in undeveloped rural areas. We need to have more emphasis that birth spacing is more important for mother and child health rather than a method of family planning, it has been a survival strategy for mother and child [6].

In the Holy Quran Surah 31, Verse 14, Allah Almighty says: "his mother bore him by strain after strain. His nursing (suckling) period lasts two years. Be grateful to Me and to your parents". It clearly indicates that a mother should feed her child for two years it can only be possible if a women did not became pregnant in this duration but due to lack of awareness they are unable to do so. The role of religious leaders was also not satisfactory in this regard. People are unaware of the teaching of Islam in this phenomenon. Culturally we are living in a society where people wish to have more children not giving importance to have space in pregnancies. Myths and misconceptions about the contraceptives which can be used for the purpose of birth spacing boost the problem as in [4].

\section{OBJECTIVES}

The main objectives of this research study are to understand the community perception about birth spacing and to suggest measures for improving birth spacing.

\section{MethODS}

\section{A. Universe of the Study}

District Swabi has been divided in two Tehsils; Swabi and Chota Lahore for its administrative purpose. Both the 
Tehsils have been a composition of rural and urban setups.

\section{B. Sampling Techniques and Tools of Data Collection}

The data was collected from these two tehsils according to the following steps:

Step 1: In the first step a list of all rural and urban setups in both the Tehsils had been made and four Union Councils had been selected (one rural and one urban) making it two each from each Tehsils. The selected Union Councils were as follows: Table I.

TABLE I: HUMAN DEVELOPMENT INDICATORS OF DIFFERENT COUNTRIES ACCORDING TO UNDP'S HUMAN DEVELOPMENT REPORT.

\begin{tabular}{|c|c|c|c|c|c|c|c|}
\hline Country & Pakistan & Bangladesh & Afghanistan & India & Canada & USA & Norway \\
\hline HDI Value & 146 & 146 & 175 & 136 & 11 & 3 & 1 \\
\hline Expenditure on health (\% of GDP) (\%) & 0.8 & 1.2 & 0.9 & 1.2 & 8.0 & 9.5 & 8.0 \\
\hline Under five mortality (per 1,000 live births) & 0.8 & 48 & 149 & 63 & 6 & 8 & 3 \\
\hline Life expectancy at birth (years) & 65.7 & 69.2 & 49.1 & 65.8 & 81.1 & 78.7 & 81.3 \\
\hline Adult literacy rate both sexes (\% aged 15 and above) & 54.9 & 56.8 & N.A. & 62.8 & N.A. & N.A. & N.A. \\
\hline Maternal mortality ratio (deaths of women per 100,000 live births) & 260 & 240 & 460 & 200 & 12 & 21 & 7 \\
\hline
\end{tabular}

TABLE II: NAMES OF SELECTED UNION COUNCILS WITH THEIR POPULATION SizE.

\begin{tabular}{|l|l|l|l|}
\hline Tehsil & $\begin{array}{l}\text { Union } \\
\text { Council }\end{array}$ & Structure & Population \\
\hline \multirow{2}{*}{ Swabi } & Asota Sharif & Rural & 14149 \\
\cline { 2 - 4 } & Swabi Khas & Urban & 20247 \\
\hline Chota Lahore & Sard China & Rural & 20567 \\
\cline { 2 - 4 } & Anbar & Urban & 19292 \\
\hline
\end{tabular}

Source: Population Department Khyber Pakhtunkhwa.

Step 2: In the second step we collected data from 80 respondents (20 each from each Union Council) by using purposive sampling technique, too meet the needs of the study. Thus the data had been collected from married population i.e. both male and female.

\section{FINDINGS AND DATA ANALYSIS}

After data collection the data has been analyzed and the following results have been drawn.

The Tables III shows the education level of the respondents that is out of the total 42 males $31(73.8 \%)$ were illiterate while $11(26.2 \%)$ were literate while among 38 females $29(76.3 \%)$ were illiterate and $9(23.7 \%)$ were literate which shows that majority of the respondents were illiterate.

TABLE III: EDUCATION OF THE RESPONDENTS

\begin{tabular}{|l|l|l|l|l|l|l|}
\hline Sex & Total & $\%$ & Illiterate & $\%$ & Literate & $\%$ \\
\hline Male & 42 & 52.5 & 31 & 73.8 & 11 & 26.2 \\
\hline Female & 38 & 47.5 & 29 & 76.3 & 9 & 23.7 \\
\hline Total & 80 & 100 & & & & \\
\hline
\end{tabular}

The Table IV shows that most of the respondents i.e. 40 (50\%) had no income because they were house wives while 23 (28.75\%) had their income up to 5000-15000 Pakistani Rupee (PKR) and 12 (15\%) had between 16000-25000 PKR while the remaining $5(6.25 \%)$ respondents had their income up to $26000 \mathrm{PKR}$ or more. (Whereas $1 \mathrm{US} \$$ is equal to 104 PKR).

TABLE IV: ECONOMIC CONDITIONS OF THE RESPONDENTS

\begin{tabular}{|l|l|l|}
\hline Monthly Income & Total Respondents & $\%$ \\
\hline Nil & 40 & 50.0 \\
\hline $5000-15000$ & 23 & 28.75 \\
\hline $16000-25000$ & 12 & 15.0 \\
\hline 26000 and Above & 5 & 6.25 \\
\hline Total & 80 & 100 \\
\hline
\end{tabular}

The Tables V shows that $42(52.5 \%)$ of the respondents had 4-6 children while 21 (26.25\%) of the respondents had $1-3$ children and the remaining $17(21.25 \%)$ respondents had 7 or more.

TABLE V: NUMBER OF CHILDREN OF THE RESPONDENTS

\begin{tabular}{|l|l|l|}
\hline No of Children & Total & $\%$ \\
\hline $1-3$ & 21 & 26.25 \\
\hline $4-6$ & 42 & 52.5 \\
\hline 7 and Above & 17 & 21.25 \\
\hline Total & 80 & 100 \\
\hline
\end{tabular}

TABLE VI: PERCEPTION OF THE RESPONDENTS ABOUT BIRTH SPACING.

\begin{tabular}{|l|l|l|}
\hline Reasons & Total & $\%$ \\
\hline Shyness in couple & 16 & 20.0 \\
\hline Islam Forbids & 31 & 38.75 \\
\hline Male don't like & 13 & 16.25 \\
\hline Medically not good & 18 & 22.5 \\
\hline $\begin{array}{l}\text { Misconceptions about family } \\
\text { planning methods }\end{array}$ & 02 & 2.5 \\
\hline Total & 80 & 100 \\
\hline
\end{tabular}

The Table VI shows the perception of the respondents about birth spacing and it was found that 31 (38.75\%) respondents said that Islam forbids birth spacing, while 18 $(22.5 \%)$ respondents said that the contraceptives which are used for birth spacing are not medically good and can cause medical problems in the host, $16(20.0 \%)$ said that shyness among the couples is the cause of not going for birth spacing, , $13(16.25 \%)$ respondents said that men don't like to be restrained from sexual pleasures, and the remaining 2 (2.5\%) respondents said that the contraceptives or other family planning methods used for birth planning permanently stop the reproduction ability of the couple for the future.

The Table VII shows the opinion of respondents about the main reasons of not going for birth spacing by people in Pakhtun Culture. Most of the respondents 23 (28.75\%) said that because of male dominance women are not allowed to go for birth spacing, 21 (26.25\%) said that because of lack of awareness on the part of common people about the consequences of untimely and repeated pregnancies, 17 $(21.25 \%)$ said that because of a desire of a family to have a male child they try again and again to conceive to succeed in having a male child, and $8(10 \%)$ said that due to rigid behavior of men. 
TABLE VII: REASONS FOR NOT GOING FOR BIRTH SPACING IN PAKHTUN Culture.

\begin{tabular}{|l|l|l|}
\hline Main causes & Frequency & $\%$ age \\
\hline Male dominancy & 23 & 28.75 \\
\hline Desire of male child & 17 & 21.25 \\
\hline Religious dominancy & 11 & 13.75 \\
\hline Lack of awareness & 21 & 26.25 \\
\hline Rigidness in male & 8 & 10.0 \\
\hline Total & 80 & 100.0 \\
\hline
\end{tabular}

The Table VIII shows that for 34 (42.5\%) respondents the failure of BHUs for promoting birth spacing is due to lack of interest by the staff of BHUs, for 21 (26.25\%) respondents the cause is lack of access to BHUs by common people as they are far off from their residential areas, while $16(20.0 \%)$ said that contraceptives are not available in sufficient quantity at BHUs and only $9(11.25 \%)$ said that due to non availability of concerned staff at BHUs for helping and guiding the patients about reproductive health and family planning procedures and measures.

TABLE VIII: CAUSES OF FAILURE OF BASIC HEALTH UNITS (BHUS) IN PROMOTING BIRTH SPACING.

\begin{tabular}{|l|l|l|}
\hline Causes of failure & Frequency & $\%$ age \\
\hline Lack of interest of staff & 34 & 42.5 \\
\hline $\begin{array}{l}\text { Far off from the } \\
\text { residential areas }\end{array}$ & 21 & 26.25 \\
\hline $\begin{array}{l}\text { Lack of availability of } \\
\text { contraceptives }\end{array}$ & 16 & 20.0 \\
\hline Non availability of staff & 9 & 11.25 \\
\hline Total & 80 & 100.0 \\
\hline
\end{tabular}

TABLE IX: PROBLEMS FACED IN USING CONTRACEPTIVES FOR BIRTH SPACING.

\begin{tabular}{|l|l|l|}
\hline Problems & Frequency & $\%$ age \\
\hline Difficult to understand & 41 & 51.25 \\
\hline $\begin{array}{l}\text { Negative impacts on } \\
\text { body }\end{array}$ & 13 & 16.25 \\
\hline Less reliable & 18 & 22.5 \\
\hline Not of good quality & 8 & 10.0 \\
\hline Total & 80 & 100.0 \\
\hline
\end{tabular}

The Table IX shows that most of the respondents 41 $(51.25 \%)$ had difficulty in understanding the use of contraceptives, while $18(22.5 \%)$ said that the contraceptives are not a reliable method for birth spacing, $13(16.25 \%)$ said that the use of contraceptives had negative impact on their body and $8(10 \%)$ said that these contraceptives are not of good quality.

TABLE X: SUGGESTION OF THE RESPONDENTS FOR PROMOTING BIRTH SPACING AMONG COMMON PEOPLE.

\begin{tabular}{|l|l|l|}
\hline Suggestions & Total & $\%$ \\
\hline Role of Religious Leaders & 47 & 58.75 \\
\hline LHW's interest & 12 & 15.0 \\
\hline Counseling by Doctors & 5 & 6.25 \\
\hline $\begin{array}{l}\text { Removal of Misconception } \\
\text { about Contraceptives }\end{array}$ & 16 & 20.0 \\
\hline Total & 80 & 100 \\
\hline
\end{tabular}

The Tables X explains the suggestions of the respondents for promoting birth spacing, most of the respondents 47 $(58.75 \%)$ said that religious leaders can play a vital role in this regard, while $16(20 \%)$ were of the opinion that the removal of misconceptions about the contraceptives among the local masses can solve this problem and $12(15 \%)$ said that if Lady Health Workers (LHWs) take interest in this regard, while the remaining $5(6.25 \%)$ of the respondents said that the doctor should do counseling of both males and females regarding the importance of birth spacing.

The Tables XI shows the respondents opinions regarding starting sex education in schools and colleges, most of the respondents $73(91.25 \%)$ were against of introducing sex education in schools and colleges while only $7(8.75 \%)$ supported it.

TABLE XI: ARE You IN FAVOR OF STARTING SEX EducATION AT SCHOOL/COLLEGES LEVEL?

\begin{tabular}{|l|l|l|}
\hline Sex education & Frequency & \% age \\
\hline Yes & 7 & 8.75 \\
\hline No & 73 & 91.25 \\
\hline Total & 80 & 100.0 \\
\hline
\end{tabular}

\section{SumMARY OF MAJOR FindingS}

Majority of the respondents were illiterate. Most of the respondents were house wives and had no income while the men had their income up to 5000-15000 Pakistani Rupee (PKR), where 01 US\$ is equal to 104 PKR. Most of the respondents had 4-6 children.

About the perceptions of people about birth spacing most of the respondents said that Islam forbids birth spacing. Regarding the opinion of respondents about the main reasons of not going for birth spacing by people in Pakhtun Culture, most of the respondents said that because of male dominance women are not allowed to go for birth spacing. In the views of most of the respondents the failure of BHUs for promoting birth spacing is due to lack of interest by the staff of BHUs. Most of the respondents had difficulty in understanding the use of contraceptives, while some said that the contraceptives are not a reliable method for birth spacing.

The suggestions of the respondents for promoting birth spacing includes that religious leaders can play a vital role in this regard, while some were of the opinion that the removal of misconceptions about the contraceptives among the local masses can solve this problem and some also said that if Lady Health Workers (LHWs) take interest in this regard, while the remaining respondents said that the doctor should do counseling of both males and females regarding the importance of birth spacing.

The respondents' opinions regarding starting sex education in schools and colleges, most of the respondents were against of introducing sex education in schools and colleges.

\section{DISCUSSIONS}

As majority of the respondents were illiterate so they 
were unaware about the issues of reproductive health. The women remained at home and do only household chores so they do not get any money in return and were economically dependent on the men of the family. The men's monthly income was also low (about 48US\$ - 144US\$) and a family of almost 8 persons was dependent on this income for the whole month to care for their all needs and necessities. If we take 144US\$ monthly income of a family of 8 members, it makes 0.6 US\$ per day per person which is less than a dollar a day. So the people were living very low below international poverty line which is 2 dollars a day or 208 PKR.

For most of the people Islam forbids birth spacing or family planning which is a misconception as stated in introduction by quoting a verse of Holy Quran which says that a mother should feed her child for at least two and half year and if she conceives again in two years after giving birth to a child she cannot feed her milk to the first baby which makes it against the teachings of Islam. There were also misconceptions about the contraceptives which are used for birth spacing as some reported that they are not medically good and can cause medical problems in the host and some were of the views that shyness among the couples is the cause of not going for birth spacing as they cannot discuss such issues between themselves. An interesting findings and to some extent true was that some of the respondents said that men don't like to be restrained from sexual pleasures. Another misconceptions found was that the contraceptives or other family planning methods used for birth planning permanently stop the reproduction ability of the couple for the future. This shows that majority of the people had misconceptions about the religion and thus for them the use of contraceptives and the other means of family planning was against the teachings of Islam. There were also misconceptions about the contraceptives and their impact on human body and reproductive ability of the couple.

The Pakhtun are tribal people living on the Pak-Afghan borders. Their traditions and culture are rigid and primitive. They do not allow their women to go out of their houses thus females are mostly illiterate and have no say in family matters. Men are considered supreme in power, prestige and honour. Most of the respondents were of the opinion that because of male dominance in Pakhtun culture, women are not allowed to opt for birth spacing, as the women cannot argue and convince their male counterpart to have less number of children or to let them get their energies back to conceive again.

Basic Health Units (BHUs) are set up by government in communities as small medical units for caring the immediate medical needs of people; they specifically are meant to offer outdoor medical facilities and health education and awareness to the people of the area they serve. The failures of BHUs for promoting birth spacing were found in opinion of the respondents as due to lack of interest by the staff of BHUs, lack of access to BHUs by common people as they are far off from their residential areas, and as contraceptives are not available in sufficient quantity at BHUs and due to non availability of concerned staff at
BHUs for helping and guiding the patients about reproductive health and family planning procedures and measures. As these BHUs are not effectively performing the duties of providing preventive and curative medical help and not raising awareness of people on health issues so people are ignorant of the usage and effectiveness of the means of reproductive health also especially the use of contraceptives is beyond their understandings which may be also because most of the people are illiterate.

The respondents also suggested some measures to promote reproductive health and birth spacing among masses which includes that the religious leaders can play a vital role in this regard to clear misunderstandings about the teachings of Islam. Some were of the opinion that the removal of misconceptions about the contraceptives among the local masses can solve this problem and some also said that if Lady Health Workers (LHWs) take interest in this regard and du, while the remaining respondents said that the doctor should do counseling of both males and females regarding the importance of birth spacing. Majority of the respondents were found against introducing sex education in schools and colleges pertaining it to their views that it is unIslamic.

\section{CONCLUSION}

The common people especially living in rural and remote areas of Pakistan should be made aware of their reproductive health issues. The role of BHUs and the lady health workers is of paramount importance in this respect. As they can motivate and convince people to have proper life styles and care for the needs of the women and children of the house regarding their health and hygiene. The role of religious leaders can also be quiet important in this regard as they can explain people about this phenomenon because Islam also support birth spacing with its teachings. Village Health committees and Lady Health Worker's program should be made more functional in order to remove the misconceptions about the contraceptives which are used for birth spacing purpose. The contraceptives should be available free of cost to the people because sometimes the officials which are giving the contraceptives take some money in return which the poor people cannot afford and also the quality of contraceptive measures available should also be enhanced.

\section{REFERENCES}

[1] S. Bhalotra and A. V. Soest, Birth Spacing, Fertility and Neonatal Mortality in India: Dynamics, Frailty and Fecundity, Germany: Tilburg University, 2006, pp. 47.

[2] United Nations Development Program. (2013). The Rise of the South: Human Progress in a Diverse World. Human Development Report [Online]. Available: http://www.hdr.undp.org

[3] R. Nathpati, Family Planning, New Delhi: A.P.H Publishing Corporation, 2008, pp. 22.

[4] A. R. Omran, Family Planning in the Legacy of Islam, London: Routledge Publication, 1992, pp. 1.

[5] Z. Ebrahim. (2009). Pakistan to promote birth spacing among women. [Online]. Available: http://southasia.oneworld.net

[6] S. O. Rutstein, "Trends in birth spacing," DHS Comparative Reports, Calverton, Maryland, USA: ICF Macro, no. 28, 2011. 


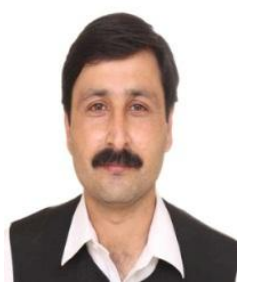

Muhammad Ibrar is a Ph.D. scholar, lecturer an coordinator at Department of Social Work, Institute of Social Work, Sociology and Gender Studies, University of Peshawar, Khyber Pakhtunkhwa, Pakistan. He has work experience of both public and private sector of Pakistan for more than five years. He has also participated and presented research papers in many national and international conferences.

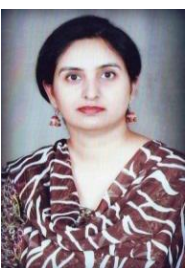

Raazia Hassan Naqvi is a Ph.D. scholar at Department of Social Work, Institute of Social Work, Sociology and Gender Studies, University of Peshawar, Khyber Pakhtunkhwa, Pakistan. She is also working as lecturer with Department of Social Work, University of the Punjab, Lahore, Pakistan. She has a work experience of almost twelve years with public and private sector of Pakistan. She has participated and presented research papers in many national and international conferences. 